\title{
Making weight: a case study of two elite wrestlers
}

\author{
Nicola Maffulli, MD, PhD, DSMSA \\ University of London, Institute of Child Health, Respiratory and Anaesthetic Unit, Sports Medicine Laboratory, \\ London, UK and University of Naples, First Medical School, Department of Physiology, Section of Sports \\ Physiopathology, Naples, Italy
}

\begin{abstract}
Two mature elite Sambo wrestlers were studied during a 22-day pre-European Championship period, during which they were to lose weight and maintain their top physical performance characteristics. During this time the athletes underwent intensive training coupled with a hypocaloric diet. Both lost approximately $8 \%$ of their initial body weight, while maintaining their pre-weight loss maximum oxygen uptake, anaerobic threshold and maximum isometric strength. These variables therefore increased when expressed relative to the lower body weight. Isometric endurance and short-term sprinting ability, however, were compromised by the weight-loss regimen, decreasing by up to $7 \%$ and $13 \%$ respectively. Following a well-planned weight-reduction programme coupled with serious training, aerobic power and isometric strength were unaffected and/or improved, but prolonged anaerobic exercise performance was impaired.
\end{abstract}

Keywords: wrestling, weight loss

'Making weight' is the practice by which athletes practising combat sports and lightweight rowing lose body weight to compete at a lower weight category. This is accomplished by a combination of dieting, exercise and dehydration ${ }^{1}$. Donation of a pint of blood for weight reduction has also been reported ${ }^{2}$.

When undergoing a weight-reduction programme, wrestlers may dehydrate as well as lose some lean tissue $^{3,4}$. Despite the potential dangers related to 'making weight', wrestlers continue these practices, being confident that a lower body weight will make them relatively faster and stronger ${ }^{5}$.

The results of physiological monitoring of the weight-reduction programme for competitive purposes in two elite adult wrestlers are reported.

\section{Subjects and methods}

The wrestlers studied were two mature Caucasian athletes, in excellent physical condition. They had been training for several years before the study began. Both had been 'making weight' once or twice a year for 11 years (Athlete 1 , aged 30 years at the time of study) and 14 years (Athlete 2, aged 32 years

Address for correspondence: N. Maffulli, Department of Orthopaedics, Newham General Hospital, Glen Road, Plaistow, London E13 8RU, UK

(C) 1992 Butterworth-Heinemann Ltd 0306-3674/92/020107-04 at the time of study). Athlete 1 had gradually progressed from the $57 \mathrm{~kg}$-weight category to the $62 \mathrm{~kg}$-weight category. Athlete 2 had progressed from the $52 \mathrm{~kg}$ - to the $57 \mathrm{~kg}$-weight category. Neither had experienced great difficulties in 'making weight', or used performance-enhancing drugs. Their respective weights and heights at the beginning of the study were 67 and $62 \mathrm{~kg}$, and 1.63 and $1.60 \mathrm{~m}$. Their competition weights were 62 and $57 \mathrm{~kg}$.

\section{Diet}

According to previous experience, the athletes estimated that 3 weeks would be sufficient to reach the desired weight. They followed a strictly regimented hypocaloric diet containing a daily average of $5860 \mathrm{~kJ}(1400 \mathrm{kcal})$, composed of an average of $65 \%$ carbohydrate, $23 \%$ protein and $12 \%$ fat (about half of which was from olive oil). The subjects were prescribed the diet and issued with a commercially available food weighing scale. All food items were weighed by the subjects, who recorded the weight in a $\log$ book provided by the author. All dietary records were analysed using standard tables ${ }^{6}$. During the weight-loss period, both athletes also took irregular vitamin supplements. They trained 7-10 times per week, with 3-5 sessions of continuous or interval running training, and the remaining sessions of specific Sambo training. They were under the constant medical supervision of the author, and were actively discouraged from undertaking any dehydration practice or from restricting their fluid intake, which was measured using a 200-ml cup, and averaged 2.891/day for Athlete 1 and 2.711/day for Athlete 2.

\section{Laboratory testing}

The athletes underwent laboratory testing twice a week during the study period. Maximal oxygen uptake determination $\left(V_{\mathrm{O}_{2}} \mathrm{max}\right)$, anaerobic threshold determination (AT), and measurement of bilateral maximal voluntary isometric contraction (MVIC) of the knee extensor muscles and the elbow flexor muscles were performed during a single testing session on three consecutive Fridays and on the Wednesday before the competition at the weekend. Another weekly testing session consisted of muscular resistance testing of the non-dominant upper and lower limb for the above-mentioned muscle groups, and uphill sprinting to exhaustion. This session was 
carried out on three consecutive Mondays before the competition.

\section{Anthropometric measurements}

A full set of anthropometric measurements was taken before each testing session. Additionally, body weight was measured the morning before the weigh-in. Weight (approximated to the nearest $100 \mathrm{~g}$ ), baseline-only height (approximated to the nearest $\mathrm{mm}$ ), bilateral upper arm and upper thigh circumference, tricipital, bicipital, subscapular and suprailiac skinfolds were measured ${ }^{6}$. Harpenden anthropometric equipment (Holtain, Harpenden, UK) was used. All measurements were taken in duplicate by the author (who can duplicate the above readings within $5 \%$ in more than two-thirds of all repeated measurements ${ }^{7}$ ).

The average of the two measurements per side was used for the determination of body fat. This was calculated from the mathematical average of the bilateral measurements of skinfold thickness using the equations developed by Durnin and Womersley ${ }^{8}$.

The subjects were well acquainted with all of the laboratory procedures, having been tested on several occasions unrelated to the present study. All procedures were performed in an air-conditioned laboratory at a temperature of $20( \pm 1)^{\circ} \mathrm{C}$.

\section{Maximal oxygen uptake and anaerobic threshold determination}

After 10-15 min of warm up at $6 \mathrm{~km} \mathrm{~h}^{-1}$, the maximal oxygen uptake and anaerobic threshold (AT) determination tests started. The protocol used consisted of continuous running on an electrically driven treadmill starting at $8 \mathrm{~km} \mathrm{~h}^{-1}$ at a fixed slope of $3^{\circ}$. Speed was increased by $0.5 \mathrm{~km} \mathrm{~h}^{-1}$ every minute until the athletes reached exhaustion. Heart rate (HR) was recorded with skin electrodes, and expressed in beats $\min ^{-1}$. Expired gases were collected with a Respironics Speak-Easy III face mask (P. K. Morgan, Gillingham, UK) with two built-in one-way valves. Ventilatory parameters were determined with a turbine intake ventilometer. Expired oxygen content was determined with a model QA500 paramagnetic analyser (P. K. Morgan, Gillingham, UK), and carbon dioxide content was measured by a model 901 infrared carbon dioxide analyser (P. K. Morgan, Gillingham, UK). Data were supplied to an IBM compatible personal computer, which provided 15-s averages of oxygen consumption $\left(\dot{V}_{\mathrm{O}_{2}}\right)$ and carbon dioxide production $\left(\dot{V} \mathrm{CO}_{2}\right)$. The analysers were calibrated with gases of known concentration before and after each test. Anaerobic threshold was determined using the non-invasive method described previously ${ }^{9}$, based on the loss of linearity in the relationship between heart rate and running speed at AT. The highest $\mathrm{HR}$ reached during the $\dot{V}_{\mathrm{O}_{2} \max }$ determination test was considered to be the maximal HR.

$\dot{V} \mathrm{O}_{2 \text { max }}$ was considered to have been achieved if there was an increase in $\dot{V}_{2}$ of less than $2 \mathrm{ml} \mathrm{kg}^{-1} \mathrm{~min}^{-1}$ despite an increase in speed. If no plateau was seen, $V_{\mathrm{O}_{2} \text { max }}$ was taken as the highest
$\dot{V} \mathrm{O}_{2}$ reached if a respiratory exchange ratio greater than 1.1 had been reached, or if the HR reached was within $95 \%$ of the maximal HR of the subject ${ }^{10}$.

\section{Maximal voluntary isometric contraction (MVIC)}

Maximum voluntary isometric contraction (MVIC) strength of the elbow flexor muscles and of the knee extensor muscles was measured bilaterally using a custom-made chair ${ }^{11}$. A metal bar was attached to the front and another to the back of the chair to accommodate a compact portable gauge consisting of two silicon strain gauges (Type DDP.350.500, Kulite Sensors, London, UK) bonded to either side of the horizontal portion of a U-shaped piece of aluminium alloy forming two arms of a Wheatstone bridge ${ }^{11}$. The gauges were incorporated into an inextensible link between a cuff around the limb to be tested and a fixed point about which the link could swivel. In this way the gauge was always in the direct line of action of the force applied. When energized with $5 \mathrm{~V}$, and the output amplified on an amplifier-recorder (Model 88182202 09, Series 552, Gould, Lyon, France), the gauges responded linearly to force within the range 73.5-1200 N (Reference 12). The height of the anterior and posterior bars was adjusted for each athlete so that the gauges were coplanar with a horizontal plane passing through the wrist and ankle joints. The apparatus was calibrated before and after each test by suspending known weights $(7.5-119.6 \mathrm{~kg}$ ) from the strain gauge, and reading the deflection shown by the Gould amplifier-recorder.

Muscular strength was determined by reading the deflection produced, multiplying it by the gain at which the measurement had been carried out, and multiplying the value thus obtained by 9.8 to express it in newtons.

\section{Isometric strength of the elbow flexor muscles}

The athlete's arms rested on a shelf, and the chair back and shelf were adjusted so that the subject sat upright with the back supported and the shoulder and elbow joint at $90^{\circ}$. The forearm was kept in full supination, and the strain gauge connected to the wrist through a padded protective splint. Lap and chest straps prevented forward movement of the subject during the contraction.

\section{Isometric strength of the knee extensor muscles}

The strain gauge was attached to the back of the chair, coplanar with the ankle joint of the subject. The hips and knees were kept at $90^{\circ}$ of flexion, and the strain gauge was connected to the ankle to be tested through a padded protective splint. During the measurement the subject's arms were kept crossed in front of the chest. Elevation of the hips was prevented by lap and chest straps.

\section{Testing procedure}

The athletes were already well accustomed to the procedure. They were asked to produce four maximal MVIC for each limb. Each athlete performed the testing procedure in one of the two following orders, at random: right arm - left arm - right leg - left leg; or right leg - left leg - right arm - left arm. Four attempts 
were recorded and measured, and the highest used in all the work described in this paper.

This method of MVIC recording has been shown to be reliable and reproducible ${ }^{13,14}$, and there are few problems in fully recruiting the quadriceps or the elbow flexors ${ }^{15}$.

\section{Muscular resistance test}

The subjects were asked to maintain for as long as possible an isometric contraction at $66 \%$ of their MVIC of their non-dominant upper and lower limb, according to the latest MVIC determination test ${ }^{16}$. They were encouraged verbally during the test. The upper and lower limbs were tested randomly.

\section{Uphill sprinting to exhaustion}

One hour after the completion of the muscular resistance test, and after a jogging warm-up of $10-15 \mathrm{~min}$, subjects were asked to run at a speed of $20 \mathrm{~km} \mathrm{~h}^{-1}$ at a slope of $15 \%$ until exhaustion. They were encouraged verbally during the test.

\section{Statistics}

Data were fed to an IBM-compatible personal computer, and analysed using SYSTAT ${ }^{17}$. Descriptive statistics were calculated. Data were analysed using a repeated-measures one- or two-way analysis of variance (ANOVA) design. Significance was set at the $P<0.05$ level.

\section{Results}

\section{Anthropometric measurements}

Body weight declined steadily during the study, reaching the required target on the day of the weigh-in. This was accomplished by diet and exercise alone until $48-36 \mathrm{~h}$ before the weigh-in, at which time the subjects restricted their liquid intake. The two athletes lost $5 \mathrm{~kg}$ each, i.e. 8.1 and $8.8 \%$ of their total body weight respectively $(P<0.01)$ (Figure 1$)$. The loss of lean body mass of $2.2 \%$ and $3 \%$ of their initial body weight was not significant.

The percentage of body fat decreased steadily during the study (Athlete 1 from 12.2 to $6 \%$; Athlete 2 from 11.3 to $5 \%$ ). Circumferences showed a similar pattern: the upper arm circumference decreased from

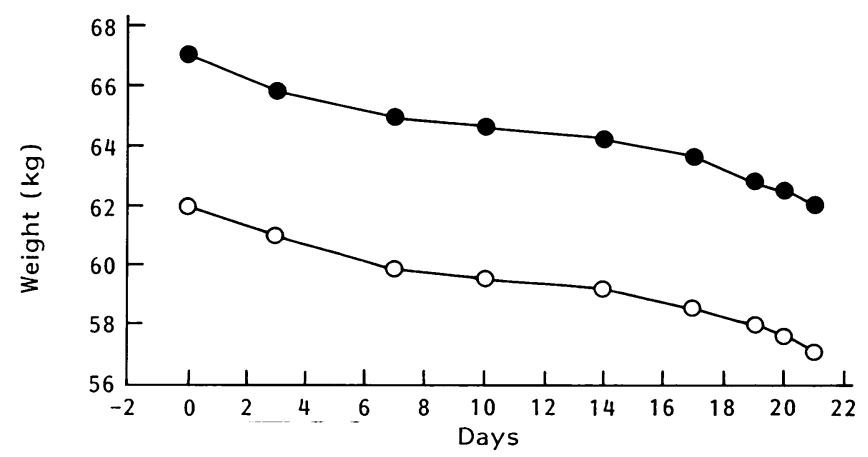

Figure 1. Changes in body weight throughout the experimental period $\bullet-$ Athlete 1 ; ○—० Athlete 2
30.1 to $28.7 \mathrm{~cm}$ (right side) and from 29.8 to $28.4 \mathrm{~cm}$ (left side) in Athlete 1, and from 29.7 to $28.1 \mathrm{~cm}$ (right side) and from 29.3 to $28.0 \mathrm{~cm}$ (left side) in Athlete 2; the upper thigh circumference decreased from 56.2 to $55.0 \mathrm{~cm}$ (right side) and from 56.0 to $54.7 \mathrm{~cm}$ (left side) in Athlete 1, and from 51.1 to $48.3 \mathrm{~cm}$ (right side) and from 50.6 to $47.8 \mathrm{~cm}$ (left side) in Athlete 2 .

\section{$\dot{V}_{\mathrm{O}_{2} \max }$ and AT}

$\dot{V}_{\mathrm{O}_{2 \max }}$ in absolute values increased slightly (Athlete 1, from $4.1601 \mathrm{~min}^{-1}$ to $4.2001 \mathrm{~min}^{-1}$; Athlete 2 , from $3.6601 \mathrm{~min}^{-1}$ to $\left.3.7861 \mathrm{~min}^{-1} ; P>0.05\right)$, but increased significantly in relation to body weight (Athlete 1, from 62.1 to $67.2 \mathrm{ml} \mathrm{kg}^{-1} \mathrm{~min}^{-1}$; Athlete 2, from 60 to $63.1 \mathrm{ml} \mathrm{kg}^{-1} \mathrm{~min}^{-1} ; P<0.05$ ). The $\dot{V}_{\mathrm{O}_{2}}$ at which AT occurred increased but not significantly (Athlete 1, from 2.953 to $3.101 \mathrm{l} \mathrm{min}^{-1}$; Athlete 2, from 2.671 to $2.8631 \mathrm{~min}^{-1}$ ). The percentage of $\dot{\mathrm{V}}_{2 \text { max }}$ at which AT occurred was almost constant at just above $71 \%$.

Maximal HR remained constant throughout the study period, range $178-181$ beats $\mathrm{min}^{-1}$ (Athlete 1) and $182-185$ beats $\mathrm{min}^{-1}$ (Athlete 2). HR at AT remained equally constant, range $167-169$ beats min $^{-1}$ for Athlete 1, and 171-174 beats min $^{-1}$ in Athlete 2 .

MVIC, muscular resistance test of the non-dominant upper and lower limb, and uphill sprinting to exhaustion

In absolute terms, MVIC for the upper limbs increased significantly (Athlete 1 , from 288 to $341 \mathrm{~N}$; Athlete 2, from 274-322 N; $P<0.05$ ), while in the lower limbs it remained constant. However, when the results were expressed per $\mathrm{kg}$ body weight, the difference reached the 0.001 level of significance (upper limb: Athlete 1, 4.3-5.5 N; Athlete 2, 4.4-5.6 N; lower limb: Athlete 1, 10.9-11.9 N; Athlete $2,11.3-12.3 \mathrm{~N}$ ). The increase was of similar magnitude in both athletes.

The strength endurance test revealed a nonsignificant decrease in endurance at the end of the weight loss period (Athlete 1, 59.2-56.2s, $-5 \%$; Athlete 2, 61.1-56.8s, $-7 \%$ ).

Uphill sprinting time was similarly slightly reduced at the end of the study period (Athlete 1, 29.2-26.2 s, $-10 \%$; Athlete 2, 31.1-26.8s, $-13 \%$ ).

\section{Discussion}

This study shows that the two wrestlers studied were able to lose about $8 \%$ of their initial body weight and still retain top aerobic and maximum isometric strength performance. However, the weight-loss regimen undertaken compromised uphill sprinting endurance and isometric strength endurance, two important indicators of anaerobic capacity. Caloric consumption remained constant during the study, and weight loss was accomplished by a high quantitative and qualitative level of physical training. In this way the subjects came within reach of the target weight $24 \mathrm{~h}$ before the weigh-in, and were able to lose the further weight by restricting fluid intake and exercise-induced sweating. 
Combat sports are alternated aerobic-anaerobic activities, requiring dexterity, skill, balance, strength and power. While maximum aerobic power in absolute terms remained unchanged, it increased relative to body weight. The percentage of $\dot{V}_{\mathrm{O}_{2}} \max$ at which AT occurred increased slightly. This could be due to greater amounts of energy produced by aerobic mechanisms, or an indication that the subjects' glycogen levels were reduced. As muscle biopsies were not taken, no definite statement can be made.

Anaerobic capacity (uphill sprinting and strength endurance) decreased. This may be due to the probable depletion of muscle glycogen in the last phases of the dieting programme, coupled with the loss of lean mass.

MVIC remained stable in absolute terms, but increased relative to body weight. Maximal HR remained constant. Semistarved subjects and patients suffering from anorexia nervosa exhibit decreased maximal heart rates with incremental exercise $^{18}$, probably as an effect of protein malnutrition ${ }^{19}$. This did not happen in the two athletes, and their protein intake was probably adequate to cover the needs of mature adults ${ }^{20}$.

Repeated weight cycling may increase the difficulty with which weight is lost in subsequent cycles, increase food efficiency and induce a decline in resting metabolic rate in adolescent wrestlers ${ }^{21}$, even though recent evidence suggests that this does not seem to be the case in elite young wrestlers ${ }^{22}$. Wrestlers with a low resting metabolic rate may need to undergo more frequent and severe dieting cycles to 'make weight'. In the two athletes considered, weight loss was not perceived as showing increasing difficulty, despite the length of time that they had been practising the sport.

The studies performed on weight loss in wrestlers have mainly considered adolescent athletes who were undergoing weight-reduction practices many times each season ${ }^{21,22}$. One study has been carried out on a single adult elite olympic free-style wrestler who lost about $7 \mathrm{~kg}$ to compete at the limit of the $48 \mathrm{~kg}$ weight category ${ }^{23}$. As in that case, the athletes taking part in the present study were losing weight only for national and international tournaments. More recently, a group of 12 collegiate wrestlers was studied during a period of loss of $6 \%$ of their body weight in 4 days ${ }^{24}$. Such a sudden severe weight loss had a negative effect on the athletes from both a physiological and a psychological viewpoint.

In conclusion, while acknowledging that the practice of cutting weight using severe caloric and fluid restriction, dehydration and self-induced vomiting $^{24,25}$ is dangerous and lessens physical performance capability, the well programmed combination of limitation of energy intake and serious endurance, resistance and technical training used by the two athletes studied actually resulted in significant gains in some physiological parameters when expressed per unit of body weight.

The rate of weight loss is probably important if adipose tissue is to be lost $\mathrm{t}^{26}$. If the rate is too high, lean tissue can be lost unnecessarily, and deleterious effects may be obtained.

\section{References}

1 Tipton CM, Tcheng TK, Zambraski EJ. Iowa wrestling study: weight classification systems. Med Sci Sports 1976; 8: 101-4.

2 Hursh LM. Food and water restriction in the wrestler. J Am Med Assoc 1979; 241: 915-16.

3 Katch FI, Michael AD. Body composition of high school wrestlers according to age and weight category. Med Sci Sports 1971; 3: 190-4.

Ribisl P. When wrestlers shed pounds quickly. Phys Sportsmed 1974; 2: 536-40.

5 Yarrows SA. Weight loss through dehydration in amateur wrestling. J Am Diet Assoc 1988; 88: 491-3.

6 Pennington JAT, Church HN. Bowes and Church's Food Values of Portions Commonly Used. Philadelphia: J. B. Lippincott, 1980.

7 Cameron N. The Measurement of Human Growth. Beckenham: Croom Helm, 1984: 56-99.

8 Durnin JVGA, Womersley J. Body fat assessed from total body density and its estimation from skinfold thickness. Measurement on 481 men and women aged 16 to 72 years. Br J Nutr 1974; 32: 77-92.

9 Maffulli N, Sjodin B, Ekblom B. A laboratory method for non-invasive determination of the anaerobic threshold. J Sports Med Phys Fitness 1987; 27: 419-23.

10 Astrand P-O, Rodahl K. Textbook of Work Physiology. New York: McGraw-Hill, 1986

11 Davies J, Parker DF, Rutherford OM, Jones DA. Changes in strength and cross-sectional area of the elbow flexors as result of isometric strength training. Eur J Appl Physiol 1988; 57: $667-70$.

12 Jones DA, Parker DF. Development of a portable strain gauge to measure human isometric muscle strength. J Physiol 1989; 415: 11P.

13 Parker DF. Factors controlling the development and strength of human skeletal muscle. PhD Thesis, University of London, UK. 1989.

14 Parker DF, Round JM, Sacco P, Jones DA. A cross-sectional survey of upper and lower limb strength in boys and girls during childhood and adolescence. Ann Hum Biol 1990; 17: 199-211.

15 Rutherford OM, Jones DA, Newham DJ. Clinical and experimental application of the percutaneous twitch superimposition technique for the study of human muscle activation J Neurol Neurosurg Psychiatr 1986; 49: 1288-91.

16 Hepburn D, Maughan RJ. Glycogen availability as a limiting factor in the performance of isometric exercise. J Physiol 1982 325: 52P-53P.

17 Leland W. Systat: The System for Statistics. Evanston, Illinois, USA: SYSTAT, 1988.

18 Fohlin L, Freyschues U, Bjarke B et al. Function and dimensions of the circulatory system in anorexia nervosa. Acta Paediatr Scand 1978; 67: 11-16.

19 Schocken DD, Holloway JD, Powers PS. Weight loss and the heart. Effects of anorexia nervosa and starvation. Arch Int Med 1989; 149: 877-81.

20 Burke LM, Dead RSD. Sports nutrition. Approaching the nineties. Sports Med 1989; 8: 80-100.

21 Steen SN, Oppliger RA, Brownell KD. Metabolic effects of repeated weight loss and regain in adolescent wrestlers. $J \mathrm{Am}$ Med Assoc 1988; 260: 47-50.

22 Melby CL, Schmidt WD, Corrigan D. Resting metabolic rate in weight-cycling collegiate wrestlers compared with physically active, noncycling subjects. Am J Clin Nutr 1990; 52: 409-14.

23 Widerman PM, Hagan RD. Body weight loss in a wrestler preparing for competition: a case report. Med Sci Sports Exerc 1982; 14: 413-18.

24 Horswill CA, Hickner RC, Scott JR et al. Weight loss, dietary carbohydrate modifications, and high intensity, physical performance. Med Sci Sports Exerc 1990; 22: 470-6.

25 Woods ER, Wilson CD, Masland RP. Weight control methods in high school wrestlers. J Adol Health Care 1988; 9: 394-7.

26 Hickson JF, Johnson TE, Lee W, Sidor RJ. Nutrition and the precontest preparations of a male bodybuilder. J Am Diet Assoc 1990; 90: 264-7. 